\title{
Epigenetic Alterations of IL-6/STAT3 Signaling by Placental Stem Cells Promote Hepatic Regeneration in a Rat Model with $\mathrm{CCl}_{4}$-induced Liver Injury
}

\author{
Jieun Jung ${ }^{1,2}$, Ji Wook Moon ${ }^{3}$, Jong-Ho Choi ${ }^{1}$, Yong Woo Lee ${ }^{3}$, Sun-Hwa Park ${ }^{3}$, Gi Jin Kim ${ }^{1}$ \\ ${ }^{1}$ Department of Biomedical Science, CHA University, Seongnam, ${ }^{2}$ Department of Nanobiomedical Science, Dankook University, \\ Cheonan, ${ }^{3}$ Institute of Human Genetics, Department of Anatomy, Korea University College of Medicine, Seoul, Korea
}

Background: Human chorionic plate-derived mesenchymal stem cells (CP-MSCs) isolated from the placenta have been reported to demonstrate therapeutic effects in animal models of liver injury; however, the underlying epigenetic mechanism of this effect has not been elucidated. Thus, we investigated whether CP-MSCs influence epigenetic processes during regeneration of the injured liver.

Methods: CP-MSCs were engrafted into a carbon tetrachloride $\left(\mathrm{CCl}_{4}\right)$-injured rat model through direct transplantation into the liver (DTX), intrasplenic transplantation (STX), and intravenous transplantation via the tail vein (TTX). Non-transplanted (NTX) rats were maintained as sham controls. Liver tissues were analyzed after transplantation using immunohistochemistry, western blot analysis, and quantitative methylation-specific polymerase chain reaction. Proliferation and human interleukin-6 (hIL-6) enzyme-linked immunosorbent assays were performed using $\mathrm{CCl}_{4}$-treated hepatic cells that were co-cultured with CP-MSCs.

Results: The Ki67 labeling index, cell cyclins, albumin, IL-6, and gp130 levels were elevated in the CP-MSC transplantation groups. The concentration of hIL-6 in supernatants and the proliferation of $\mathrm{CCl}_{4}$-treated rat hepatic cells were enhanced by co-culturing with CP-MSCs $(\mathrm{p}<0.05)$, while the methylation of $I L-6 / I L-6 R$ and STAT3 by CP-MSC transplantation decreased.

Conclusion: These results suggest that administration of CP-MSCs promotes IL-6/STAT3 signaling by decreasing the methylation of the IL-6/SATA3 promoters and thus inducing the proliferation of hepatic cells in a $\mathrm{CCl}_{4}$-injured liver rat model. These data advance our understanding of the therapeutic mechanisms in injured livers, and can facilitate the development of cell-based therapies using placenta-derived stem cells.

Keywords: Placenta stem cells, Liver regeneration, Transplantation routes, IL-6 signaling, DNA methylation

\footnotetext{
Accepted for publication May 4, 2015, Published online May 30, 2015

Correspondence to Sun-Hwa Park

Institute of Human Genetics, Department of Anatomy, Korea University College of Medicine, 126-1, Anam-dong 5-ga, Seongbuk-gu, Seoul 136-705, Korea

Tel: +82-2-2286-1152, Fax: +82-2-929-5696

E-mail: parksh@korea.ac.kr

Co-Correspondence to Gi Jin Kim

Department of Biomedical Science, CHA University, 689 Sampyeong-dong, Bundang-gu, Seongnam 463-400, Korea

Tel: +82-31-881-7145, Fax: +82-31-881-7249

E-mail: gjkim@cha.ac.kr
}

(a) This is an open-access article distributed under the terms of the Creative Commons Attribution Non-Commercial License (http://creativecommons.org/ licenses/by-nc/4.0/), which permits unrestricted non-commercial use, distribution, and reproduction in any medium, provided the original work is properly cited. 


\section{Introduction}

Liver failure is the most severe clinical consequence of liver disease and may result from massive hepatic destruction due to repeated and chronic damage to the liver. Liver cirrhosis and its associated complications are major causes of morbidity and mortality worldwide (1). At present, orthotopic liver transplantation is essentially the only accepted therapeutic method for treating irreversible liver disease; however, this procedure has many limitations (e.g., scarcity of donors and the invasive nature of the procedure) (2). For this reason, transplantation of hepatocytes has been suggested as a useful therapeutic approach for the treatment of liver disease (3). Nevertheless, several challenges must be overcome before cell-based clinical applications can fulfill their therapeutic promise and potential, such as low yields, limited sources of donors, and clinical complications (4).

Stem cell-based therapeutic strategies using several types of stem cells have recently been introduced in regenerative medicine for hepatic diseases (5). Among the various stem cells, bone marrow-derived mesenchymal stem cells (BM-MSCs) have been investigated as a source of hepatic cells for liver regeneration for their potential to differentiate into hepatic epithelial cells in vitro and in vivo $(6,7)$. However, BM-MSCs have low yields, decreased cell numbers that are dependent on donor age, and the collection procedure is invasive (8). Furthermore, it has been reported that BM-MSCs cause negative effects such as development of malignancies, e.g., human epithelial cancers and sarcomas $(9,10)$, and transformation into hepatic fibrogenic cells (11); this illustrates the need to identify alternative sources of stem cells with better safety and efficacy profiles.

Human placenta-derived mesenchymal stem cells (hPD-MSCs) have attracted attention in the stem cell research field. hPD-MSCs are readily available and easily procured without invasive procedures or ethical controversy, and their characteristics are similar to those of BM-MSCs (12). Recently, it was reported that hPD-MSCs have the ability to differentiate into several cell lineages (13), including cells with immunomodulatory properties (14). Many types of placental stem cells exist in various anatomical locations (e.g., human amniotic epithelial cells, human amniotic mesenchymal stromal cells, and human chorionic mesenchymal stromal cells) (13, 15). hPD-MSCs express albumin and can differentiate into hepatogenic cells; furthermore, they can perform several typical functions of hepatocytes after hepatogenic differentiation (16, 17). In addition, hPD-MSCs have immunomodulatory properties and play a role in preserving fetal tolerance; as a result, host organs tend to show weaker immune responses $(14,17)$. Therefore, hPD-MSCs are considered a promising and novel source of cells for regenerative medicine and cell-based therapies in clinical applications.

Regeneration of injured liver tissues involves complex, systemically co-regulated mechanisms such as escape and protection from the injury-causing factor, anti-fibrotic effects, regulation of inflammation, and promotion of regeneration $(16,18,19)$. Interestingly, Interleukin-6 (IL-6)/gpl30 signaling has been shown to promote liver regeneration and is a well-known cytokine for hepatoprotection; however, IL-6 is also a representative proinflammatory cytokine $(20,21)$. The role of IL-6 in promoting regeneration was demonstrated by the suppression of liver regeneration in IL-6 knockout mice. Mice lacking IL-6 have weakened DNA responses after a partial hepatectomy, which lead to liver necrosis and liver failure, and these effects were reversed by treatment with recombinant IL-6 before resection (22). Researchers have determined that the cytokine-dependent pathways as well as many identified proteins connected to these pathways are crucial for liver regeneration (23). The downstream effect of IL-6 signaling is triggered when IL-6 binds to its specific membrane-bound IL-6 receptor (IL-6R), forming an IL-6/IL-6R complex, which then induces dimerization of the receptor subunit gp130 and activates the JAK family of proteins via phosphorylation of signal transducers and activators of transcription (STATs) (24).

Epigenetic alteration is believed to play a crucial role in a variety of biological processes. Abnormal DNA methylation is generally considered a contributing factor to disease progression. Therefore, modulating epigenetic regulatory mechanisms may be an important treatment strategy for many diseases. It is well known that stem cells such as MSCs exhibit dynamic gene expression based on their microenvironments because they are undifferentiated and immature cells (25), and many researchers have analyzed the gene expression patterns of stem cells under differentiation or self-renewal conditions using high-throughput tools (e.g., microarray, proteomics) (26). Epigenetic gene regulation is essential for maintaining cell type-specific expression, such as stemness genes, and this mode of regulation does not cause changes in the underlying DNA sequences (27). This characteristic is especially true in the case of fibrotic diseases, where epigenetic modifications such as DNA methylation and histone modifications have been observed. This newly emerging field links epigenetic modifications to the pathogenesis of fibrosis (28).

We have previously demonstrated that human chorionic plate-derived mesenchymal stem cells (CP-MSCs) isolated 
from normal-term placentas exhibited several therapeutic effects, including anti-fibrosis, anti-inflammation, anti-apoptosis, and pro-autophagic effects, via transplantation in a rat model with cirrhosis $(16,29)$. In the present study, we further investigated how the different therapeutic effects of CP-MCS were presented in relation to different transplantation routes, namely, direct transplantation into the liver (DTX), intrasplenic transplantation (STX), and intravenous transplantation via the tail vein (TTX), in a carbon tetrachloride $\left(\mathrm{CCl}_{4}\right)$-injured rat liver model via the IL-6/ signal transducer and activator of transcription 3 (STAT3) signaling pathway. In addition, we investigated the functional roles of CP-MSCs in epigenetic regulation of IL-6/STAT3 signaling during liver regeneration in $\mathrm{CCl}_{4}$-injured rats.

\section{Materials and Methods}

\section{Cell culture}

The collection of samples and their use for research purposes were approved by the Institutional Review Board of the CHA General Hospital, Seoul, Korea (2006-27). All participating women provided written informed consent prior to the collection of samples. Placentas were collected from women who were free of medical, obstetric, and surgical complications and who had delivered to term $(\geq 37$ gestational weeks). CP-MSCs were harvested as described previously (16). Briefly, CP-MSCs were separated from the inner side of the chorioamniotic membrane of the placenta and collected. Cells scraped from the membrane were treated with $0.5 \%$ collagenase IV (Sigma-Aldrich; St. Louis, MO, USA) for $30 \mathrm{~min}$ at $37^{\circ} \mathrm{C}$. The harvested cells were cultured in Ham's F-12 medium/Dulbecco's modified Eagle's medium (DMEM; Invitrogen; Carlsbad, CA, USA) that was supplemented with $10 \%$ fetal bovine serum (FBS; Invitrogen), 1\% penicillin/streptomycin (P/S; Invitrogen), $25 \mathrm{ng} / \mathrm{mL}$ human fibroblast growth factor-4 (hFGF-4; Sigma-Aldrich), and $1 \mu \mathrm{g} / \mathrm{mL}$ heparin (Sigma-Aldrich). WI-38 cells (human normal fibroblasts) were purchased from the American Type Culture Collection (Manassas, VA, USA), and WB-F344 (rat liver epithelial cells) and T-HSC/Cl-6 cells (rat hepatic stellate cells transformed with simian virus 40) were donated by Dr. J. Jang (Seoul National University, Seoul, Korea) and cultured at $37^{\circ} \mathrm{C}$ in alpha-minimum essential medium ( $\alpha$-MEM; Invitrogen) supplemented with $10 \% \mathrm{FBS}$ and $1 \% \mathrm{P} / \mathrm{S}$.

\section{Rat model of $\mathrm{CCl}_{4}$-induced liver injury and transplantation of CP-MSCs}

Six-week-old male Sprague-Dawley rats (Orient Bio Inc.;
Seongnam, Korea) were maintained in an air-conditioned animal house under specific pathogen-free conditions and allowed unlimited access to chow and water. Liver failure was induced by intraperitoneal (i.p.) injection of the hepatotoxicant $\mathrm{CCl}_{4}(1.6 \mathrm{~g} / \mathrm{kg}$; Sigma-Aldrich) dissolved in corn oil twice a week for 9 weeks. Control rats $(n=5)$ were injected with an equal volume of corn oil alone, while animals in the negative control group $\left(\mathrm{CCl}_{4} ; n=5\right)$ were sacrificed immediately after the administration of $\mathrm{CCl}_{4}$ for 9 weeks. CP-MSCs $\left(2 \times 10^{6}\right.$ cells, passages $\left.8 \sim 10\right)$ were transplanted by direct transplantation into the liver (DTX, $n=17$ ), intrasplenic transplantation (STX, $n=19$ ), or intravenous transplantation via the tail vein (TTX, $n=21$ ), and non-transplanted (NTX) rats were maintained as sham controls $(n=19)$. To prevent immune rejection, the rats were injected i.p. with an immunosuppressant, FK506 (0.2 $\mathrm{mg} \cdot \mathrm{kg}^{-1} \cdot \mathrm{day}^{-1}$; Prograf; Astellas Pharma Korea, Inc.; Korea), every day from the day after CP-MSC transplantation until the end of the experiment. The liver tissues were collected at 1, 2, and 3 weeks post-transplantation from animals in the transplantation groups and from NTX rats. We conducted all animal experimental procedures using protocols that were consistent with the National Institutes of Health Guidelines.

\section{Genomic DNA extraction and sodium bisulfite DNA modification}

Genomic DNA was extracted using the QIAamp DNA Mini Kit (Qiagen; Valencia, CA, USA). The tissue samples were ground by $3-\mathrm{mm}$ diameter punches and then mixed with $700 \mu \mathrm{L}$ of a lysis buffer containing $20 \mu \mathrm{g} / \mathrm{mL}$ Labo Pass protease K (Cosmo Gene Tech.; Seoul, Korea), 20 $\mathrm{mM}$ Tris-HCl (pH 8.0), $5 \mathrm{mM}$ EDTA (pH 8.0), $400 \mathrm{mM}$ $\mathrm{NaCl}$, and $1 \%$ sodium dodecyl sulfate (SDS) solution (Sigma-Aldrich). The mixed samples were then incubated in a $42^{\circ} \mathrm{C}$ incubator overnight. After incubation, the genomic DNA was purified via phenol/chloroform extraction. Genomic DNA was eluted in $100 \mu \mathrm{L}$ of water and quantified with a NanoDrop ND-100 device (Thermo Fisher Scientific; Waltham, MA, USA). Two micrograms of genomic DNA in a volume of $20 \mu \mathrm{L}$ of RNase-free water was bisulfite-converted using the EpiTect ${ }^{\circledR}$ fast DNA bisulfite kit (QIAGEN; Hilden, Germany). Bisulfite conversion was performed according to the manufacturer's instructions. The reaction was performed by sufficient mixing of the DNA with $85 \mu \mathrm{L}$ of the bisulfite mix solution and $35 \mu \mathrm{L}$ of DNA protection buffer in $200-\mu \mathrm{L}$ polymerase chain reaction (PCR) tubes at room temperature (RT). 
Table 1. Primers for quantitative methylation specific PCR (QMSP)

\begin{tabular}{|c|c|c|c|}
\hline Genes & Gene banks & Region & Primer sequences $\left(5^{\prime} \rightarrow 3^{\prime}\right)$ \\
\hline $\mathrm{r} \beta$-actin & NC_005111.2 & $-520 \sim-360$ & $\begin{array}{l}\text { Forward; TTGGAGAAGAGTTATGAGTTGTTTG } \\
\text { Reverse; TAACCTCCAACATTAATCACCTTTAA }\end{array}$ \\
\hline rlL-6R & NC_005101.3 & $-239 \sim+3$ & $\begin{array}{l}\text { Forward; TTTTAGTATCGGTTTTTTAAATGTTTC } \\
\text { Reverse; CATAATTCCTTCTACGTAAAACGAC }\end{array}$ \\
\hline rSTAT3 & NC_005109.2 & $-359 \sim-229$ & $\begin{array}{l}\text { Forward; TTGAGTTTTTAGTAGGATATTTCGT } \\
\text { Reverse; СТСССТАAАTTAАСTATTCCGAA }\end{array}$ \\
\hline
\end{tabular}

\section{Quantitative methylation-specific PCR (QMSP)}

In brief, the bisulfite-converted genomic DNA was amplified by quantitative real-time PCR using a 7000 HT Real-Time PCR System (Applied Biosystems; Foster City, CA, USA) according to the manufacturer's instructions. The methylation primers were designed using MethPrimer software (http://www.urogene.org/methprimer/), and the primers used for QMSP are displayed in Table 1.

The PCR was performed using a 96-well optical tray in a final volume of $20 \mu \mathrm{L}$. The reaction mixture consisted of $5 \mu \mathrm{L}$ of $2 \mathrm{X}$ Maxima ${ }^{\circledR}$ SYBR Green/ROX qPCR master mix (Thermo Fisher Scientific), $250 \mathrm{nM}$ of each primer, and $30 \mathrm{ng}$ of bisulfite-converted DNA template. The QMSP program began at $50^{\circ} \mathrm{C}$ for $2 \mathrm{~min}, 95^{\circ} \mathrm{C}$ for $10 \mathrm{~min}$, followed by 45 cycles at $95^{\circ} \mathrm{C}$ for $15 \mathrm{sec}$ and $60^{\circ} \mathrm{C}$ for 1 min. After PCR, a thermal melt profile was performed to examine the homogeneity of the PCR application. Each DNA sample was analyzed in duplicate, and the mean quantity was used for further analysis. Relative quantification of the amplified gene levels of the bisulfite-converted genomic DNA sample was performed by measuring the threshold cycle $\left(\mathrm{C}_{\mathrm{T}}\right)$ values of the target genes and $\beta$-actin. The mean quantity of the genes was divided by the mean quantity of the $\beta$-actin gene, which was used to normalize the input DNA. The negatives for $\beta$-actin were excluded from the methylation analysis. A known concentration of the bisulfite-converted genomic DNA was prepared at 1 , $1 / 4,1 / 16$, and $1 / 64$ via serial dilutions and used to generate the standard curve for quantification. Genomic DNA was treated with M.ssI (New England Biolabs [NEB]; Beverly, MA, USA) according to the manufacturer's recommendations and used as a positive control. DNA methylation according to M.ssI treatment was verified using the methylation-sensitive restriction enzyme BstUI (NEB).

\section{Western blot analysis}

Liver tissues from animals in each group were homogenized and lysed in protein lysis buffer (Intron Biotechnology; Korea). Equal amounts of proteins from individual animals were pooled with protein samples obtained at 1 ,
2, and 3 weeks post-transplantation. The protein lysates were then loaded onto $10 \%$ or $12 \%$ SDS polyacrylamide gels for the detection of IL-6, gp130, cyclin A, cyclin E, albumin, and actin. Separated proteins were transferred onto PVDF membranes, which were then incubated overnight at $4^{\circ} \mathrm{C}$ with antibodies against IL-6 (Abcam Biotechnology Inc; Santa Cruz, CA, USA; 1:800), gp130 (Santa Cruz Biotechnology Inc.; 1:100), cyclin A (Abcam; 1:1000), cyclin E (BioLegend; San Diego, CA, USA; 1:2500), albumin (Sigma-Aldrich; 1:5000). or actin (Santa Cruz Biotechnology Inc.; 1:1000). The membranes were then incubated with secondary antibody (horseradish peroxidase-conjugated anti-mouse IgG; Bio-Rad Laboratories; 1:5000) or anti-rabbit IgG (Bio-Rad Laboratories; 1:5000)) for $1 \mathrm{~h}$ at RT in an orbital shaker. After washing, bands were detected using enhanced chemiluminescence reagent (Amersham Biosciences; Arlington Heights, IL, USA).

\section{Immunostaining}

To analyze the proliferation activity in tissues following the transplantation of CP-MSCs, liver tissues were fixed and embedded in paraffin. The right lobes were then serially sectioned at a thickness of $5 \mu \mathrm{m}$. The sections were then treated with $3 \% \mathrm{H}_{2} \mathrm{O}_{2}$ in methanol to block endogenous peroxidase activity, and antigen retrieval was achieved by microwaving in a $0.1 \mathrm{M}$ sodium citrate buffer. The slides were then incubated with an anti-Ki67 monoclonal antibody (Novocastra; Newcastle, UK; $1: 50$ ) at $4^{\circ} \mathrm{C}$ overnight followed by a 30-min incubation with the secondary antibody at RT. The sections were counterstained with Mayer's hematoxylin, and the Ki67 labeling index (Ki-LI) represented the percentage of hepatocytes with Ki67-positive nuclei relative to the total number of hepatocytes in the randomly selected sections (six fields per rat at $100 \times$ magnification).

\section{ELISA analysis}

WB-F344 and T-HSC/Cl-6 cells were seeded in 24-well culture plates (BD Biosciences; San Jose, CA, USA) at $1.5 \times 10^{4}$ cells/well. After stabilization for $24 \mathrm{~h}$, the cells were treated 
with $6 \mathrm{mM} \mathrm{CCl}_{4}$ for $3 \mathrm{~h}$ at $37^{\circ} \mathrm{C}$. CP-MSCs and WI-38 cells were then seeded at $3 \times 10^{4}$ cells on Transwell inserts (BD Biosciences) and cultured for $24 \mathrm{~h}$ prior to co-culturing. After $\mathrm{CCl}_{4}$ treatment, WB-F344 and T-HSC/Cl-6 cells were washed with medium three times and co-cultured for $24 \mathrm{~h}$ with inserts containing CP-MSCs or WI-38 cells in $\alpha$-MEM that was supplemented with $10 \% \mathrm{FBS}$ and $1 \% \mathrm{P} / \mathrm{S}$. The cell culture supernatants from the upper and lower chambers were harvested, and the concentrations of human IL-6 (hIL-6) were measured using an ELISA kit (BD Biosciences). Naive medium and supernatants from CP-MSCs, WI-38 cells, and $\mathrm{CCl}_{4}$-treated but not co-cultured WB-F344 and THSC/Cl-6 cells were used as controls.

To analyze the proliferation activities of WB-F344 and T-HSC/Cl-6 hepatic cells, the cells were seeded in 24-well culture plates (BD Biosciences) at $1.5 \times 10^{4}$ cells per well. After stabilization for $24 \mathrm{~h}$, the cells were treated with 6 $\mathrm{mM} \mathrm{CCl} 4$ for $3 \mathrm{~h}$ at $37^{\circ} \mathrm{C}$. CP-MSCs and WI-38 cells (1.5, 3 , or $7 \times 10^{4}$ cells) were seeded on Transwell inserts (BD Biosciences) and cultured for $24 \mathrm{~h}$ prior to co-culturing. After $\mathrm{CCl}_{4}$ treatment, WB-F344 and T-HSC/Cl-6 cells were washed with medium three times and co-cultured for $24 \mathrm{~h}$ with inserts containing CP-MSCs or WI-38 cells. The proliferation of WB-F344 and T-HSC/Cl-6 cells was measured using a BrdU ELISA kit (Roche; Mannheim, Germany). Non-CCl 4 -treated, non-co-cultured cells, and $\mathrm{CCl}_{4}$-treated, non-co-cultured cells were used as controls.

\section{Statistical analysis}

Statistical analyses were performed using the SAS software (ver. 9.1; SAS Institute; Cary, NC, USA). The data were analyzed using either one-way or two-way ANOVA. The fold changes in Col I/28s rRNA expression ratios were the dependent variables and were analyzed by two-way ANOVA. The means were calculated for each condition and defined by the following variables: treatment route (DTX, STX, TTX, or NTX) and post-transplantation time $(1,2$, or 3 weeks). Specific contrast analysis was performed using the LSD post-hoc test, and the results are presented as the means \pm standard deviation (SD). Quantitative methylation was determined by the methylation ratio (PMR) percentage, and the PMR value was defined as [(gene) sample / ( $\beta$-actin) sample] / [(gene) M.ssI / ( $\beta$-actin) M.ssI $] \times 100$. The significance of the differences of PMR between the treatment routes and post-transplantation times was defined by a $t$-test, which was used to compare the group means for the control and $\mathrm{CCl}_{4}$-injured rats. Values of $\mathrm{p}<0.05$ were considered indicative of statistical significance.

\section{Results}

\section{Promotion of hepatic regeneration through transplantation or co-culture of CP-MSCs}

We examined whether transplantation of CP-MSCs could enhance hepatic cell proliferation and liver regeneration in a $\mathrm{CCl}_{4}$-injured liver model by analyzing hepatic expression of proteins involved in liver regeneration and cell-cycle regulation. To investigate whether CP-MSCs promoted proliferative activities in the $\mathrm{CCl}_{4}$-injured rat liver, Ki-67 immunohistochemistry was performed on liver tissues (Fig. 1). The greatest numbers of Ki67-positive cells were observed in the STX group, followed by the DTX, TTX, and NTX groups. In the STX group, approximately $56 \sim 58 \%$ of cells were $\mathrm{Ki}-67$ positive, which was a significantly higher proportion than that found in the DTX group at 1 and 3 weeks post-transplantation, and in the TTX and NTX groups at 1, 2, and 3 weeks post-transplantation $(\mathrm{p}<0.05)$. In the DTX group, approximately 49 $52 \%$ of the cells were Ki67-positive, significantly higher than those in the TTX and NTX groups $(\mathrm{p}<0.05)$. Approximately $36 \sim 44 \%$ of cells in the TTX group were Ki67-positive, which was a significantly higher percentage than that of the NTX group $(\mathrm{p}<0.05)$, where the proportion was below 30\% across the 3-week study period (Fig. 1B). In addition, the levels of cell cycle-related proteins (e.g., cyclins A, E) and albumin were higher in the transplantation groups than in the NTX group (Fig. 1C).

Furthermore, we performed proliferation analyses to investigate if co-culture with CP-MSCs could promote the proliferation of injured rat hepatic cells in vitro. WB-F344 and T-HSC/Cl-6 cells were treated with $6 \mathrm{mM} \mathrm{CCl}_{4}$ for $3 \mathrm{~h}$ and co-cultured with CP-MSCs or WI-38 cells, and the proliferation of both rat hepatic cell lines was then analyzed by BrdU ELISA (Fig. 2A, B). The rate of proliferation was significantly higher in the $\mathrm{CCl}_{4}$-injured, WB-F344, and T-HSC/Cl-6 cells that were co-cultured with CP-MSCs than in cells cultured alone $(p<0.05)$. Furthermore, the rate of proliferation of WB-F344 cells was significantly higher when co-cultured with $3 \times 10^{4}$ or $7.5 \times 10^{4}$ of CP-MSCs than when they were co-cultured with identical numbers of WI-38 cells ( $p<0.05$; Fig. $2 \mathrm{~A})$. In addition, the rate of proliferation of T-HSC/Cl- 6 cells was significantly higher when co-cultured with $1.5 \times 10^{4}$ or $3 \times 10^{4} \mathrm{CP}-\mathrm{MSC}$ s than when they were co-cultured with identical numbers of WI-38 cells ( $<<0.05$; Fig. 2B).

\section{Activation of IL-6 signaling by transplantation or co-culture of CP-MSCs}

Expression of IL-6, which is known to be essential for 
A
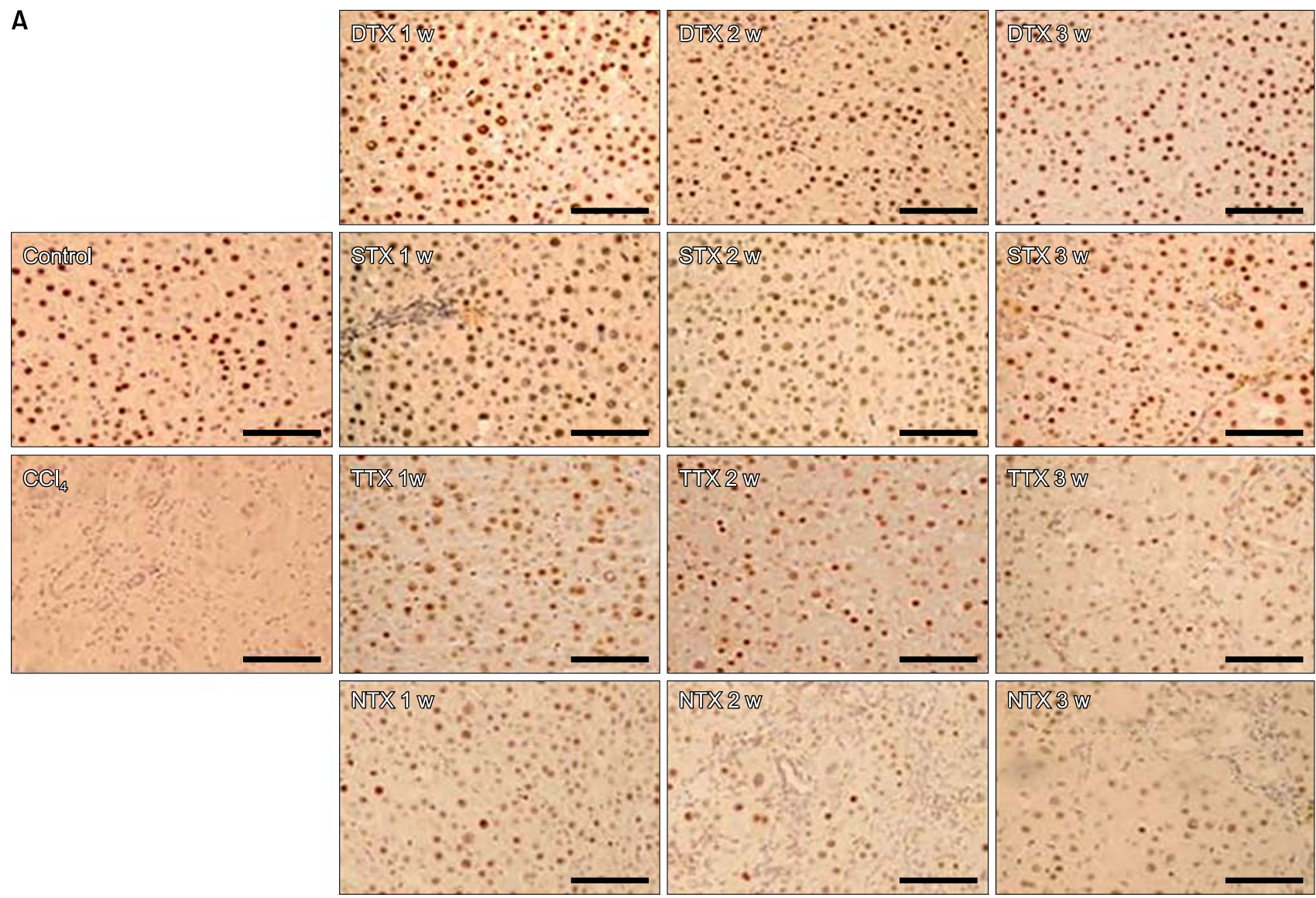

B

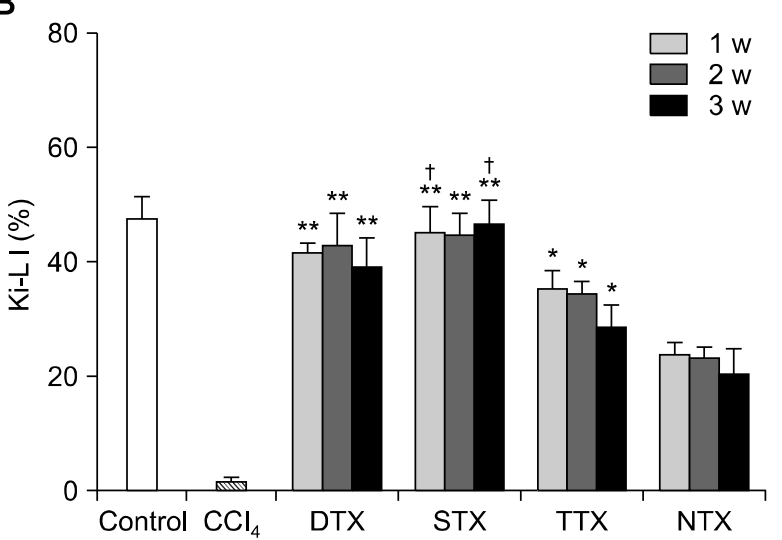

C

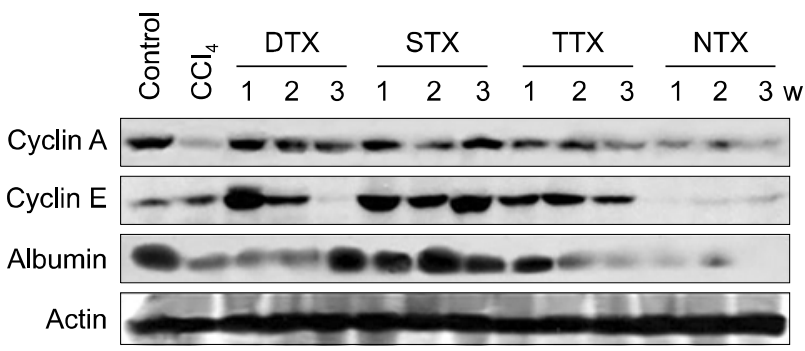

Fig. 1. Proliferative activity of CP-MSCs post-transplantation depends on the transplantation route. (A) Measurement of proliferative activity in liver tissues from rats in the control, $\mathrm{CCl}_{4}$, transplantation, and NTX groups through immunohistochemical analysis of Ki67. Scale bar $=50$ $\mu \mathrm{m}$. (B) Ki-LI represents the percentage of hepatocytes with Ki67-positive nuclei of the total number of hepatocytes. Data are expressed as the mean \pm SD. ${ }^{*} p<0.05$ when compared to the NTX group; ${ }^{* *} p<0.05$ when compared to the TTX and NTX groups; ${ }^{\dagger} p<0.05$ when compared to the DTX group. (C) Protein levels of liver cyclin A, cyclin E, and albumin in the control, $\mathrm{CCl}_{4}$, transplantation, and NTX groups were analyzed by western blotting. Actin was used as a loading control.

liver regeneration $(20,30)$, and gp130, a known IL-6 receptor (30), were at the highest levels at 1,2 , and 3 weeks post-transplantation in the STX group, and were higher in the DTX and TTX groups than in the NTX rats (Fig.
3A). These results showed an improvement in liver function that was verified by increased expression of albumin in the transplantation groups, with the STX group displaying the highest increase in albumin levels during the 

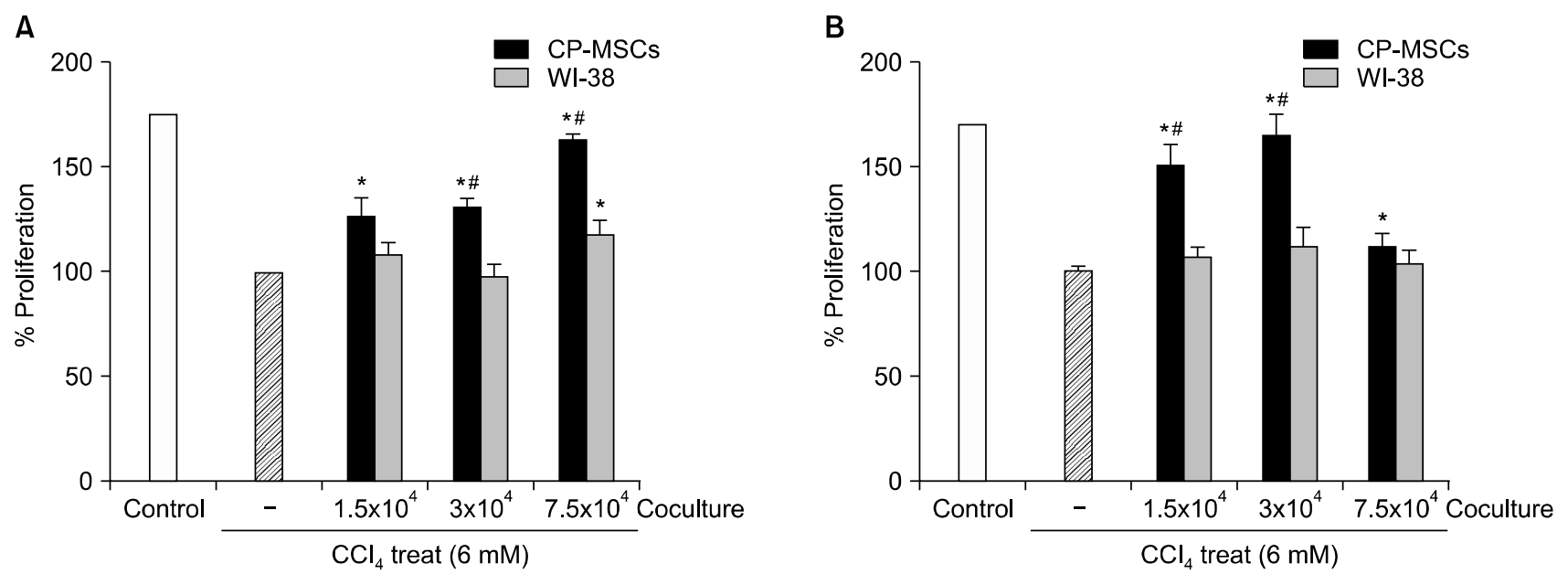

Fig. 2. Effect of CP-MSC co-cultivation on the cell proliferation of hepatic cells damaged by $\mathrm{CCl}_{4}$. (A) Proliferation assay of WB-F344 cells co-cultured with CP-MSCs and WI-38 cells for $24 \mathrm{~h}$ after treatment with $6 \mathrm{mM} \mathrm{CCl}_{4}$ for $3 \mathrm{~h}$ at $37^{\circ} \mathrm{C}$ by BrdU ELISA. Data represent the mean \pm SD. ${ }^{*}$ indicates significant differences compared to non-co-cultured cells $\left({ }^{*} p<0.05\right)$; and ${ }^{\#}$ indicates significant differences compared to WI-38 cells $\left({ }^{\sharp} \mathrm{p}<0.05\right)$. (B) Proliferation assay of T-HSC/Cl-6 cells co-cultured with CP-MSCs and Wl-38 cells for $24 \mathrm{~h}$ after treatment with $6 \mathrm{mM} \mathrm{CCl}_{4}$ for $3 \mathrm{~h}$ at $37^{\circ} \mathrm{C}$ by BrdU ELISA. Data are expressed as the mean $\pm \mathrm{SD}$. ${ }^{*}$ indicates significant differences compared to

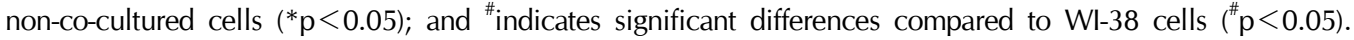

3-week study period. These findings suggest that CP-MSCs enhanced hepatic cell proliferation and liver regeneration through regulation of IL-6 signaling and the cell cycle, and STX was the most effective transplantation route for liver regeneration.

To determine if CP-MSCs could promote IL-6-mediated regeneration or proliferation of hepatic cells, as suggested by our in vivo data (Fig. 3A), we co-cultured CP-MSCs and WI-38 cells with two different types of rat hepatic cells that had been treated with $\mathrm{CCl}_{4}$. After treatment with $\mathrm{CCl}_{4}, \mathrm{WB}-\mathrm{F} 344$ rat liver epithelial cells and T-HSC/Cl-6 rat hepatic stellate cells were co-cultured with CP-MSCs or WI-38 cells in a Transwell system for $24 \mathrm{~h}$. Cell culture supernatants from the upper and lower chambers were then analyzed for hIL-6 levels by ELISA. hIL- 6 was not detected in the naive medium or the culture media of WBF344 and T-HSC/Cl-6 cells that were cultured alone. However, the expression levels of hIL-6 were significantly higher in the culture media of co-cultures of CP-MSCs with both rat hepatic cell lines compared to the culture medium from CPMSCs that were cultured alone $(\mathrm{p}<0.05)$. Interestingly, hIL-6 levels were only increased in the culture medium from T-HSC/Cl-6 cells that were co-cultured with WI-38 cells and not with WB-F344 cells $(\mathrm{p}<0.05)$. Furthermore, hIL-6 expression levels were significantly higher in the culture medium from WB-F344 cells that were co-cultured with CPMSCs compared to the culture medium from WB-F344 cells co-cultured with WI-38 cells $(p<0.05)$ (Fig. 3B). These results indicated that co-culture with CP-MSCs induced IL-6 production in damaged hepatic cells, implying that a correlation exists between increased levels of IL- 6 and enhanced proliferation of rat hepatic cells damaged by hepatotoxicants.

\section{Effect of transplanted CP-MSCs on the epigenetic alteration of the IL-6 signaling pathway during the promotion of liver regeneration}

We hypothesized that increased IL-6/gp130 expression during liver regeneration by CP-MSC transplantation was possibly enhanced by dynamic changes in IL-6-mediated, epigenetic signaling. Because IL-6-related, epigenetic processing is an important aspect of liver regeneration (31), we performed QMSP analysis on the promoter regions of the IL-6 receptor and IL-6 in DTX, STX, TTX, and NTX liver tissues. In general, the methylation levels of the IL-6 receptor and IL-6 were increased in $\mathrm{CCl}_{4}$-injured rat livers when compared to control rat livers $(\mathrm{p}<0.05$, Fig. 4A, B). Interestingly, we found that the methylation levels of the IL-6 receptor and IL-6 in all transplantation groups of CP-MSCs were significantly decreased. In addition, the methylation levels of their promoters were correlated with protein expression of IL-6 (Fig. 3A). The methylation patterns of STAT3 were gradually enhanced in all CP-MSC transplantation groups according to the number of weeks after transplantation $(\mathrm{p}<0.05)$; however, no significant differences for the TTX or NTX groups were observed (Fig. 4C). Methylation of SOCS3, which is a known suppressor of cytokine signaling 
A

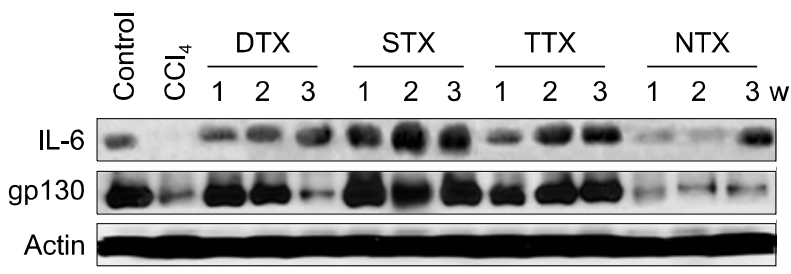

B

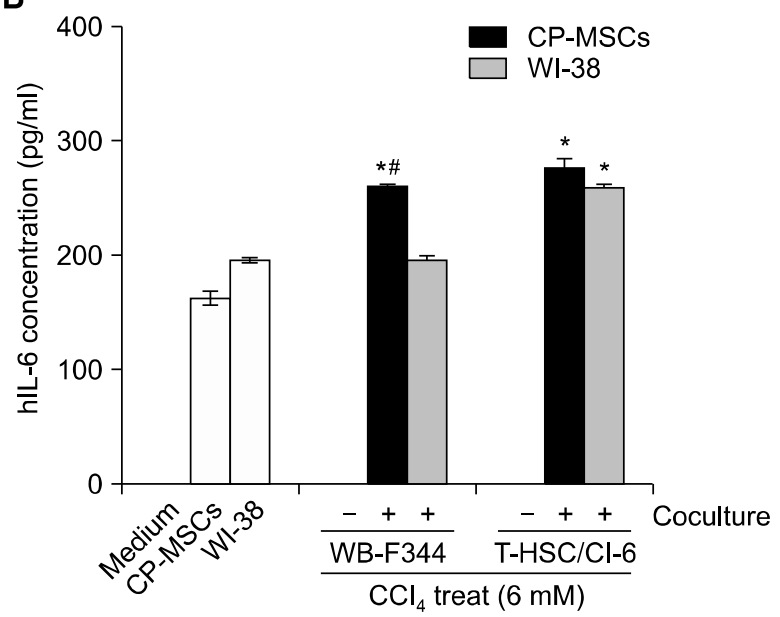

Fig. 3. Effect of CP-MSC administration on the expression of IL-6 in a $\mathrm{CCl}_{4}$-injured rat model and damaged hepatic cells. (A) Protein levels of liver IL-6 and gp130 in the control, $\mathrm{CCl}_{4}$, transplantation, and NTX groups were analyzed by western blotting. Actin was used as a loading control. (B) Levels of IL-6 in the supernatants from CP-MSCs and WI-38 cells that were co-cultured for $24 \mathrm{~h}$ with rat hepatocytes that had previously been treated with $6 \mathrm{mM} \mathrm{CCl}_{4}$ for $3 \mathrm{~h}$ at $37^{\circ} \mathrm{C}$, measured by ELISA. Data are expressed as the mean $\pm \mathrm{SD}$. ${ }^{*}$ indicates significant differences compared to non-co-cultured cells $\left({ }^{*} p<0.05\right)$; and ${ }^{*}$ indicates significant differences compared to WI-38 cells $\left({ }^{\#} \mathrm{p}<0.05\right)$.

and is induced by IL-6 expression, tended to increase during the early weeks in the DTX and STX groups (Fig. 4D). These results suggest that CP-MSC transplantation induces the expression of IL-6 in a $\mathrm{CCl}_{4}$-injured rat model by decreasing methylation levels. The different methylation patterns of IL-6/STAT signaling could lead to the different therapeutic effects of CP-MSCs that are based on transplantation routes.

\section{Discussion}

Stem cell-based therapy for liver failure using various cell sources such as human hepatocytes, cord blood cells, mesenchymal stem cells, and even embryonic stem cell-derived hepatocytes has been attempted (32). Nevertheless, their clinical applications have been hampered by several obstacles, including difficulties isolating large numbers of stem cells, the invasiveness of the procedures, and lack of understanding of the therapeutic mechanism (33). In addition, many studies have used MSCs instead of hepatocytes as alternative cell sources for treating liver failure $(7,16)$. Kuo et al. reported that undifferentiated BM-MSCs were more effective in treating $\mathrm{CCl}_{4}$-injured rat livers than BM-MSC-derived hepatocyte-like cells; however, other studies have reported the opposite result (34). Because transplanted stem cells can differentiate into functional hepatocytes and exert paracrine effects in damaged tissues and organs, stem cell-based therapies using naive stem cells may have an advantage over differentiated hepatocytes.

In previous reports, we characterized CP-MSCs and demonstrated their advantages as alternative stem cell sources $(16,17,29,35)$. We found that CP-MSCs i) displayed "stemness" and have the capacity for multi-lineage differentiation, similar to other MSCs (e.g., BM-MSCs, umbilical cord blood-derived MSCs); ii) were younger than all other adult stem cells; iii) can be obtained in large numbers and as various other cell types without the need for invasive processes or ethical debate; and iv) demonstrated immunomodulatory properties that could be advantageous in allogeneic transplantation. Based on these findings, we evaluated the optimal transplantation technology for naive CP-MSCs in $\mathrm{CCl}_{4}$-injured rats and determined their therapeutic mechanisms of action for potential use in cell-based therapies $(16,29)$. In previous reports, we demonstrated that therapeutic effects were systematically investigated by comparing DTX, STX, and TTX through homing efficiency of PKH-26 labeled CP-MSCs to damaged liver tissues and evaluated that the DTX and STX groups displayed particularly dramatic effects, with reduced collagen deposition and lower levels of bridging fibrosis in liver tissue stained with MT compared with NTX group. However, STX is most effective these pathological processes because STX showed therapeutic efficacy without surgical damage of the liver when compared to DTX (36). These results are matched to decrease the expression of type I collagen (Col I) in activated hepatic stellate cells co-cultured with CP-MSCs (16). Otherwise, the proliferation of HSC was increased by CP-MSC co-culture system compared to without CP-MSC or WI-38 co-culture system in the present study. Therefore, we can expect that CP-MSCs have multiple functions to HSC according to interaction condition between CP-MSC and HSC. So, future studies should attempt to determine the effects of CP-MSCs on hepatic regeneration through regulation of HSC activity and their functions.

Interestingly, we found that the expression of IL-6 was dramatically increased in all transplantation groups, espe- 
A

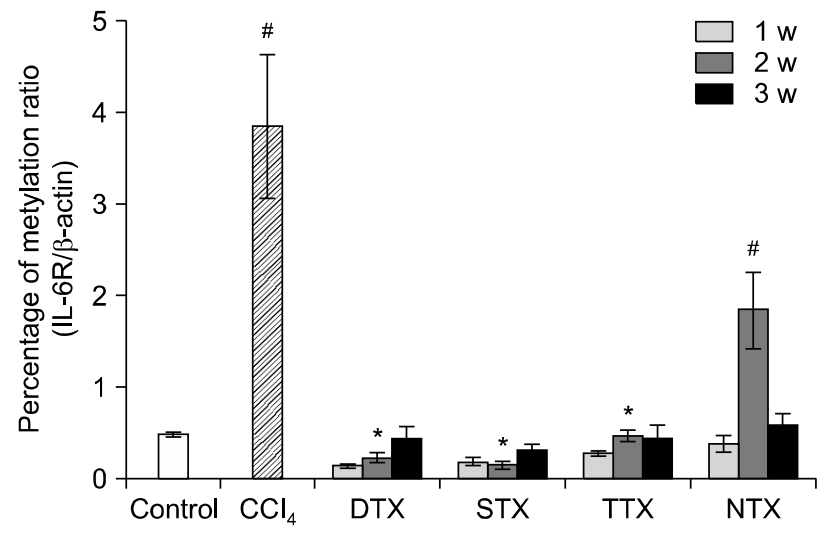

C

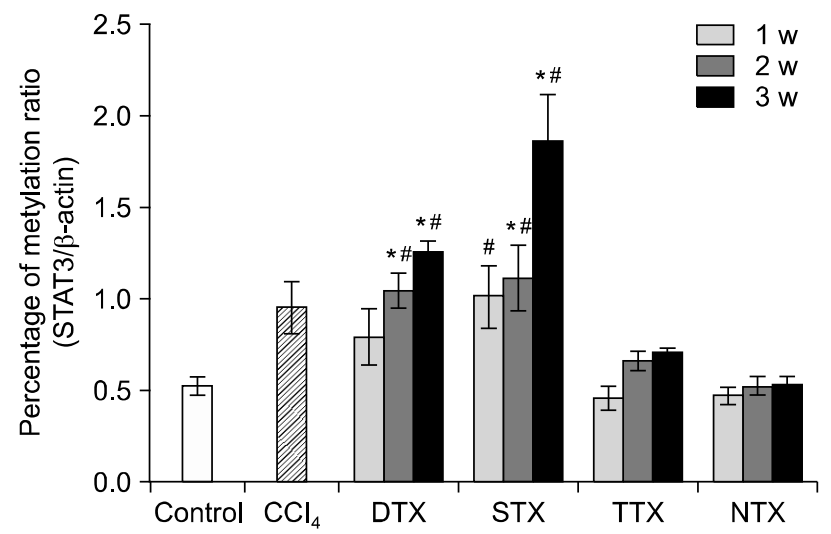

B

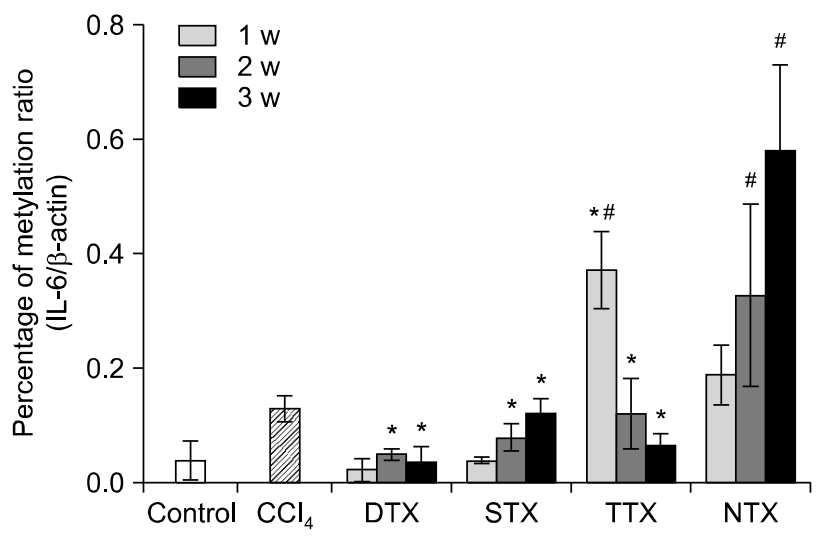

D

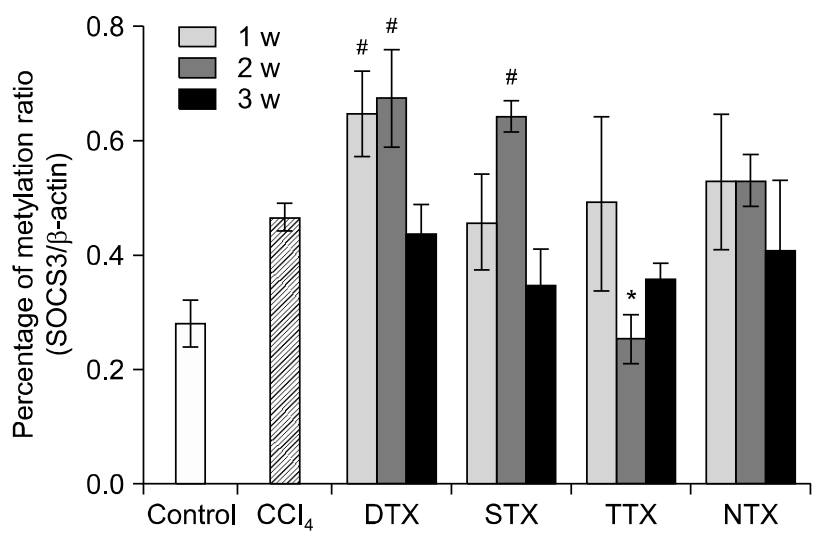

Fig. 4. Epigenetic alteration in the IL-6/STAT3 signaling pathway of a $\mathrm{CCl}_{4}$-injured rat model depends on CP-MSC transplantation. Promoter methylation of the IL-6 receptor (A), IL-6 (B), STAT3 (C), and SOCS3 (D) was measured by quantitative methylation-specific PCR. The relative quantification of the amplified methylation was determined as the percentage of methylation ratio (PMR). Each methylation was analyzed in duplicate, and the significance of the differences in PMR was defined by the $t$-test. Data are expressed as the mean \pm SD. *indicates significant differences compared to $\mathrm{CCl}_{4}$-injured livers $\left({ }^{*} \mathrm{p}<0.05,{ }^{* *} \mathrm{p}<0.01\right)$.

cially in the STX group. IL-6 is known to regulate liver regeneration through its effects on the cell cycle and/or apoptosis, which are mediated by gp130, STAT3, and mitogen-activated protein kinase (MAPK), as well as pro-inflammatory cytokines $(20,21)$. Also, there are no correlate with IL-6 in chronic liver diseases although the expression level of IL-6 in patients with liver cirrhosis was elevated (37). Instead, it has been reported that IL-6/gp130-depednt pathways are protective in chronic liver diseases model with conditional knockout animal system (Cre/loxP system) for gp130 (38) Recently, it was reported that IL-6 and stem cell factors were important for hepatocyte regeneration in damaged liver tissues (39) and that increased self-renewal of CP-MSCs was regulated by stem cell factor, which is involved in the autophagic mechanism of CP-MSCs exposed to hypoxia and is a known representative factor of stem cell niches (35). Based on these reports, we hypothesized that transplantation of CP-MSCs may improve liver regeneration by modulating IL-6 signaling.

Therefore, while the therapeutic effects of stem cells in regenerative medicine may be strongly correlated with epigenetic regulation, further elucidation of the mechanisms underlying these processes is required. We demonstrated that the mechanism of regeneration acted through the epigenetic regulation of IL-6 signaling after CP-MSC transplantation since IL-6 signaling was important for regenerative processes and could be regulated by methylation (40). We found that methylation patterns of the IL-6 receptor and IL-6 were significantly decreased in all transplantation groups (Fig. 4A, B), and these data were consistent with the western blotting results (Fig. 3A). These findings indicate that CPMSC transplantation promotes liver regeneration through the activation of IL-6 signaling 
by decreasing methylation patterns. Meanwhile, the levels of phosphorylated STAT3, a signaling molecule that acts downstream of IL-6 and gp130, were gradually increased in all CP-MSC transplantation groups depending on the number of weeks after transplantation; however, no significant differences were observed in the TTX group. These results suggest that altered methylation patterns of STAT3 may be readily blocked by potent inhibitors because the activation of STAT3 occurs as an early event and/or other factors in this molecular pathway are being modulated (21). SOCS3 is a well-known suppressor of cytokine signaling, including IL-6, and acts through negative feedback to reduce over-stimulated cytokine signaling. Therefore, the increased methylation patterns of SOCS3 at the early time points in the DTX and STX groups might be correlated with increased expression of IL-6 in the $\mathrm{CCl}_{4}$-injured rat model.

In conclusion, transplantation of CP-MSCs promoted liver regeneration through the activation of IL-6/STAT3 signaling and involved epigenetic alteration of IL-6R, IL-6, STAT3, and SOCS3. These findings clarify the mechanism of regeneration via stem-cell transplantation and provide useful guidelines for the use of transplantation technology in the treatment of liver disease.

\section{Acknowledgments}

This work was supported by a grant (14172MFDS974) from Korea Food \& Drug Administration in 2014.

\section{Potential conflict of interest}

The authors have no conflicting financial interest.

\section{References}

1. Török NJ. Recent advances in the pathogenesis and diagnosis of liver fibrosis. J Gastroenterol 2008;43:315-321

2. Lee DS, Gil WH, Lee HH, Lee KW, Lee SK, Kim SJ, Choi SH, Heo JS, Hyon WS, Kim GS, Paik SW, Koh KC, Joh JW. Factors affecting graft survival after living donor liver transplantation. Transplant Proc 2004;36:2255-2256

3. Horslen SP, Fox IJ. Hepatocyte transplantation. Transplantation 2004;77:1481-1486

4. Nussler A, Konig S, Ott M, Sokal E, Christ B, Thasler W, Brulport M, Gabelein G, Schormann W, Schulze M, Ellis E, Kraemer M, Nocken F, Fleig W, Manns M, Strom SC, Hengstler JG. Present status and perspectives of cell-based therapies for liver diseases. J Hepatol 2006;45:144-159

5. Ren G, Chen X, Dong F, Li W, Ren X, Zhang Y, Shi Y. Concise review: mesenchymal stem cells and translational medicine: emerging issues. Stem Cells Transl Med 2012;1: $51-58$
6. Cai YF, Zhen ZJ, Min J, Fang TL, Chu ZH, Chen JS. Selection, proliferation and differentiation of bone marrow-derived liver stem cells with a culture system containing cholestatic serum in vitro. World J Gastroenterol 2004; 10:3308-3312

7. Xu YQ Liu ZC. Therapeutic potential of adult bone marrow stem cells in liver disease and delivery approaches. Stem Cell Rev 2008;4:101-112

8. Rao MS, Mattson MP. Stem cells and aging: expanding the possibilities. Mech Ageing Dev 2001;122:713-734

9. Chakraborty A, Lazova R, Davies S, Bäckvall H, Ponten F, Brash D, Pawelek J. Donor DNA in a renal cell carcinoma metastasis from a bone marrow transplant recipient. Bone Marrow Transplant 2004;34:183-186

10. Yilmaz Y, Lazova R, Qumsiyeh M, Cooper D, Pawelek J. Donor $\mathrm{Y}$ chromosome in renal carcinoma cells of a female BMT recipient: visualization of putative BMT-tumor hybrids by FISH. Bone Marrow Transplant 2005;35:1021-1024

11. Houlihan DD, Newsome PN. Critical review of clinical trials of bone marrow stem cells in liver disease. Gastroenterology 2008;135:438-450

12. Barlow S, Brooke G, Chatterjee K, Price G, Pelekanos R, Rossetti T, Doody M, Venter D, Pain S, Gilshenan K, Atkinson K. Comparison of human placenta- and bone marrow-derived multipotent mesenchymal stem cells. Stem Cells Dev 2008;17:1095-1107

13. Parolini O, Alviano F, Bagnara GP, Bilic G, Bühring HJ, Evangelista $M$, Hennerbichler S, Liu B, Magatti M, Mao N, Miki T, Marongiu F, Nakajima H, Nikaido T, Portmann-Lanz CB, Sankar V, Soncini M, Stadler G, Surbek D, Takahashi TA, Redl H, Sakuragawa N, Wolbank S, Zeisberger S, Zisch A, Strom SC. Concise review: isolation and characterization of cells from human term placenta: outcome of the first international Workshop on Placenta Derived Stem Cells. Stem Cells 2008;26:300-311

14. Jones BJ, Brooke G, Atkinson K, McTaggart SJ. Immunosuppression by placental indoleamine 2,3-dioxygenase: a role for mesenchymal stem cells. Placenta 2007;28:1174-1181

15. Kim MJ, Shin KS, Jeon JH, Lee DR, Shim SH, Kim JK, Cha DH, Yoon TK, Kim GJ. Human chorionic- plate-derived mesenchymal stem cells and Wharton's jelly-derived mesenchymal stem cells: a comparative analysis of their potential as placenta-derived stem cells. Cell Tissue Res 2011;346:53-64

16. Lee MJ, Jung J, Na KH, Moon JS, Lee HJ, Kim JH, Kim GI, Kwon SW, Hwang SG, Kim GJ. Anti-fibrotic effect of chorionic plate-derived mesenchymal stem cells isolated from human placenta in a rat model of $\mathrm{CCl}_{4}$-injured liver: potential application to the treatment of hepatic diseases. J Cell Biochem 2010;111:1453-1463

17. Lee JM, Jung J, Lee HJ, Jeong SJ, Cho KJ, Hwang SG, Kim GJ. Comparison of immunomodulatory effects of placenta mesenchymal stem cells with bone marrow and adipose mesenchymal stem cells. Int Immunopharmacol 2012;13: 219-224

18. Tsai PC, Fu TW, Chen YM, Ko TL, Chen TH, Shih YH, 
Hung SC, Fu YS. The therapeutic potential of human umbilical mesenchymal stem cells from Wharton's jelly in the treatment of rat liver fibrosis. Liver Transpl 2009;15: 484-495

19. Nakamura T, Torimura T, Sakamoto $M$, Hashimoto O, Taniguchi E, Inoue $\mathrm{K}$, Sakata $\mathrm{R}$, Kumashiro R, Murohara T, Ueno T, Sata M. Significance and therapeutic potential of endothelial progenitor cell transplantation in a cirrhotic liver rat model. Gastroenterology 2007;133:91-107 e101

20. Streetz KL, Luedde T, Manns MP, Trautwein C. Interleukin 6 and liver regeneration. Gut 2000;47:309-312

21. Tiberio GA, Tiberio L, Benetti A, Cervi E, Montani N, Dreano M, Garotta G, Cerea K, Steimberg N, Pandolfo G, Ferrari-Bravo A, Mazzoleni G, Giulini SM, Schiaffonati L. IL-6 Promotes compensatory liver regeneration in cirrhotic rat after partial hepatectomy. Cytokine 2008;42:372-378

22. Cressman DE, Greenbaum LE, DeAngelis RA, Ciliberto G, Furth EE, Poli V, Taub R. Liver failure and defective hepatocyte regeneration in interleukin-6-deficient mice. Science 1996;274:1379-1383

23. Taub R. Liver regeneration: from myth to mechanism. Nat Rev Mol Cell Biol 2004;5:836-847

24. Tron K, Samoylenko A, Musikowski G, Kobe F, Immenschuh S, Schaper F, Ramadori G, Kietzmann T. Regulation of rat heme oxygenase-1 expression by interleukin- 6 via the Jak/STAT pathway in hepatocytes. J Hepatol 2006;45:72-80

25. Song L, Webb NE, Song Y, Tuan RS. Identification and functional analysis of candidate genes regulating mesenchymal stem cell self-renewal and multipotency. Stem Cells 2006;24:1707-1718

26. Menicanin D, Bartold PM, Zannettino AC, Gronthos S. Genomic profiling of mesenchymal stem cells. Stem Cell Rev 2009;5:36-50

27. Reister S, Kordes C, Sawitza I, Häussinger D. The epigenetic regulation of stem cell factors in hepatic stellate cells. Stem Cells Dev 2011;20:1687-1699

28. Robinson CM, Watson CJ, Baugh JA. Epigenetics within the matrix: a neo-regulator of fibrotic disease. Epigenetics 2012;7:987-993

29. Jung J, Choi JH, Lee Y, Park JW, Oh IH, Hwang SG, Kim KS, Kim GJ. Human placenta-derived mesenchymal stem cells promote hepatic regeneration in $\mathrm{CCl}_{4}$-injured rat liver model via increased autophagic mechanism. Stem Cells 2013;31:1584-1596

30. Wuestefeld T, Klein C, Streetz KL, Betz U, Lauber J, Buer J, Manns MP, Müller W, Trautwein C. Interleukin-6/glyco- protein 130-dependent pathways are protective during liver regeneration. J Biol Chem 2003;278:11281-11288

31. Sen GL, Reuter JA, Webster DE, Zhu L, Khavari PA. DNMT1 maintains progenitor function in self-renewing somatic tissue. Nature 2010;463:563-567

32. Woo DH, Kim SK, Lim HJ, Heo J, Park HS, Kang GY, Kim SE, You HJ, Hoeppner DJ, Kim Y, Kwon H, Choi TH, Lee JH, Hong SH, Song KW, Ahn EK, Chenoweth JG, Tesar PJ, McKay RD, Kim JH. Direct and indirect contribution of human embryonic stem cell-derived hepatocyte-like cells to liver repair in mice. Gastroenterology 2012;142:602-611

33. Russo FP, Parola M. Stem cells in liver failure. Best Pract Res Clin Gastroenterol 2012;26:35-45

34. Kuo TK, Hung SP, Chuang CH, Chen CT, Shih YR, Fang SC, Yang VW, Lee OK. Stem cell therapy for liver disease: parameters governing the success of using bone marrow mesenchymal stem cells. Gastroenterology 2008;134:21112121, 2121 e2111-2113

35. Lee Y, Jung J, Cho KJ, Lee SK, Park JW, Oh IH, Kim GJ. Increased SCF/c-kit by hypoxia promotes autophagy of human placental chorionic plate-derived mesenchymal stem cells via regulating the phosphorylation of mTOR. J Cell Biochem 2013;114:79-88

36. Jung J, Na KH, Lee MJ, Moon J, Kim GI, Jang JJ, Hwang SG, Kim GJ. Efficacy of chorionic plate-derived mesenchymal stem cells isolated from placenta in $\mathrm{CCl}_{4}$-injured rat model depends on transplantation routes. Tissue Engineering and Regenerative Medicine 2013;10:10-17

37. Tilg H, Wilmer A, Vogel W, Herold M, Nölchen B, Judmaier G, Huber C. Serum levels of cytokines in chronic liver diseases. Gastroenterology 1992;103:264-274

38. Streetz KL, Tacke F, Leifeld L, Wüstefeld T, Graw A, Klein C, Kamino K, Spengler U, Kreipe H, Kubicka S, Müller W, Manns MP, Trautwein C. Interleukin 6/gp130-dependent pathways are protective during chronic liver diseases. Hepatology 2003;38:218-229

39. Ren X, Hu B, Colletti L. Stem cell factor and its receptor, c-kit, are important for hepatocyte proliferation in wild-type and tumor necrosis factor receptor-1 knockout mice after 70\% hepatectomy. Surgery 2008;143:790-802

40. D'Anello L, Sansone P, Storci G, Mitrugno V, D'Uva G, Chieco P, Bonafé M. Epigenetic control of the basal-like gene expression profile via Interleukin-6 in breast cancer cells. Mol Cancer 2010;9:300 